\title{
PRINCIPALES LÍNEAS DE TRABAJO EN TORNO A LA DIPLOMACIA ROMANA REPUBLICANA Y SUS TRANS- FORMACIONES (s. III-II a.C.) $)^{*}$
}

\author{
PRINCIPAL LINES OF RESEARCH INTO REPUBLICAN ROMAN \\ DIPLOMACY AND ITS TRANSFORMATION DURING THE THIRD \\ AND SECOND CENTURIES BCE
}

\section{RAÚL BUONO-CORE V. ${ }^{* *}$}

RESUMEN: En el presente artículo se pretende entregar, de forma concisa y comprensible, un resumen crítico de las principales teorías, metodologías y sus problemas, que pueden ser implementadas y confrontadas en el estudio contemporáneo de la diplomacia romana republicana. Analizaremos tres aspectos: en primer lugar, desde la ciencia política realista, el rol de la diplomacia romana republicana en la instauración coercitiva y jerárquica del poder estatal romano; en segundo lugar, desde una interpretación constructivista y sociológica, el papel de la diplomacia republicana como un agente expresivo y revitalizador de los lazos simbólicos y socio-políticos senatoriales y mediterráneos, y, en tercer lugar, el rol de las comisiones senatoriales en la maduración y complejización de las labores diplomáticas.

Palabras clave: Roma, diplomacia, realismo, coercitiva, comisiones.

Aвstract: This article intends to deliver, in a concise and understandable way, a critical summary of the main theories, methodologies and problems that can be implemented and confronted in the contemporary study of republican Roman diplomacy. We will analyze three aspects: first, from realistic political science, the role of republican Roman diplomacy in the coercive and hierarchical establishment of Roman state power; secondly, from a constructivist and sociological interpretation, the role of republican diplomacy as an expressive and revitalizing agent of senatorial and Mediterranean symbolic and socio-political ties; and, thirdly, the role of senatorial commissions in the maturation and complexity of diplomatic work.

KEYWORDs: Rome, diplomacy, coercive, realism, anarchy, commissions.

Recibido: 01.03.2019. Aceptado: 31.03.2020.

* Proyecto Fondecyt $N^{\circ} 1160279$.

${ }^{\star *}$ Doctor en Historia. Profesor Emérito del Instituto de Historia de la Pontificia Universidad Católica de Valparaíso, Valparaíso, Chile, y profesor del Departamento de Historia de la Universidad de Chile. Correo electrónico: raul.buonocore@pucv.cl. Orcid: https://orcid.org/0000-0003-0065-3733. 
E $\mathrm{N}$ LOS TIEMPos que vivimos, parece ser que la tendencia general es creer, o al menos suponer, que los estudios sobre el mundo clásico son una actividad decorativa, tendencia que se opone a la mejor historiografía contemporánea, que está demostrando decididamente lo contrario. Lamentablemente, esto es prácticamente desconocido en las personas comunes, sobre todo en América, donde no se tiene un conocimiento cabal de la Antigüedad y de su desarrollo.

Las relaciones entre los seres humanos a lo largo de la historia no han sido fáciles, sus comunidades, las diferencias culturales, las religiones, el comercio, los diversos tipos de gobierno, la variedad de lenguas y costumbres, la moral y la ética, las ambiciones y frustraciones, el refinamiento y la vulgaridad, las alianzas, han hecho en muchas ocasiones difícil o compleja la mantención de relaciones pacíficas, para lo cual, desde épocas muy remotas, los pueblos crearon mecanismos que buscaran regular de algún modo convincente y responsable, lo que hoy comúnmente llamamos la convivencia internacional o un sistema de relaciones basado en normas generalmente jurídicas que garanticen una paz estable. Las primeras sociedades organizadas en un nivel superior nacen en el Mediterráneo oriental, espacio geográfico en el que surgirá la civilización griega o la primera civilización europea, que tendrá una enorme influencia en la mentalidad de culturas o civilizaciones posteriores, como es el caso de la civilización romana; ambas son consideradas pilares de lo que se estima como la cultura occidental.

Los estudios históricos sobre diplomacia griega y romana no son de larga data; si bien algunos inventarios sobre embajadas se prepararon a finales del siglo XIX, estos no tuvieron demasiada profundidad; me refiero a las listas de A. Thurm (1883) o de Th. Botten-Wobst (1876); además, este último se ocupa solo de las misiones en Roma. Hay un trabajo más reciente, el de P. Knibbe (1958), quien hace un inventario de las embajadas enviadas por el Senado romano hacia el oriente entre los años 230 y 129 a.C. Desde los primeros años del siglo XX se activan las publicaciones sobre el tema, destacando dos interesantes estudios: el primero es un catálogo de delegaciones romanas en el Mediterráneo, lamentablemente incompleto, porque se ocupa solamente del periodo que va entre el año 507 y 129 a.C., preparado por E. Krug (1916); y el segundo es el realizado por B. Schleussner (1978), quien se concentra en el análisis de los comités senatoriales de diez miembros, encargados de establecer las condiciones de la paz después de las victorias de Roma. En el caso de Roma, las indagaciones en este período tendieron a abordar el tema privilegiando los aspectos institucionales y 
jurídicos de la diplomacia a través del rol jugado por el Senado, organismo que, como sabemos, era el encargado y responsable de la política exterior. En esta línea no puedo dejar de referirme a los escritos de C. Phillipson (1911), de P. Willems (1878-1885), de P. Frezza (1938), pero sobre todo, a los de P. Catalano (1974) y F. de Martino (1972-1975).

Entre los análisis más recientes están el de B. E. Thomason (1991), quien ha investigado las misiones diplomáticas entre la Segunda Guerra Púnica y la batalla de Actium; F. Canali de Rossi (1997) lo ha hecho sobre las embajadas enviadas por los griegos a Roma durante el periodo republicano, y el registro de las relaciones diplomáticas romanas que ha venido publicando sistemáticamente desde el año 2005, del cual ya disponemos de ocho volúmenes (2005, 2007, 2013, 2014, 2016, 2017 (dos) y 2018). Destacan también las obras de C. Aulliard (2006) y de E. Torregaray (2005-2014): la primera es una valiosa síntesis de una diplomacia romana como instrumento de conquista desde la monarquía hasta las guerras samnitas, y la segunda, un trabajo sistemático sobre las características de la diplomacia y los diplomáticos romanos, como también sus problemas en Hispania. Han sido también una valiosa contribución al desarrollo de estos estudios las ediciones dirigidas por Ed. Frézouls y A. Jacquemin (1995) y de Claude Eilers (2009).

Veamos ahora el tema que me preocupa en esta ocasión. Los temores por la política expansionista de Filipo que rompe el equilibrio en oriente, condición necesaria para el desarrollo de los proyectos de Roma, justifica una intervención por restablecer ese equilibrio y la hegemonía, en un mundo diverso y con concepciones políticas alejadas de las que Roma había experimentado antes. "La continua potenciación a que una hegemonía se ve sometida si quiere subsistir, y el no reconocimiento de este papel por parte de algunos estados orientales, fueron una de las causas que condujeron a Roma por el camino del imperialismo" (Roldán, 2016, p. 283).

Siguiendo la línea de análisis de P. Veyne (1975, pp. 753-855), el ingreso romano en la política oriental amplía el horizonte romano y lo encadena a sus problemas, pero también lo enfrenta a un mundo desconocido, con los mismos mecanismos que habían movido al mundo helenístico, pero que por las características de la mentalidad romana, no le permitía entender fácilmente el concepto de equilibrio, es decir, una política de alianzas cambiantes y juegos diplomáticos complicados para mantener las fronteras, el prestigio y las influencias, frente a otros estados similares con los que tendría que convivir. Para Roma la seguridad de las fronteras no entraba en el juego diplomático, sino simplemente en la eliminación o sometimiento del enemigo. Roma entra en la política oriental como aliada de otros estados en 
lucha contra Macedonia, planteando una serie de exigencias que la victoria había hecho posible.

Algunos estudios sobre la antigüedad de la diplomacia griega y romana han permitido con el tiempo y con análisis parciales, globales y comparativos, descubrir y desarrollar alternativas aproximadas al problema de la construcción de la labor diplomática romana.

En primer lugar, desde la ciencia política realista, el rol de la diplomacia romana republicana en la instauración coercitiva y jerárquica del poder estatal romano; en segundo lugar, desde una interpretación constructiva y sociológica, el papel de la diplomacia republicana como un agente revitalizador de los lazos simbólicos y socio-políticos senatoriales mediterráneos; y en tercer lugar, desde un estudio histórico más acotado, el rol de las comisiones senatoriales en la maduración y complejidad de las labores diplomáticas republicanas.

El marco temporal de este estudio abarca entre los años 229 a 168 a.C., pues entre esas fechas los autores de las corrientes y escuelas a las cuales nos referiremos han encontrado transformaciones e hitos relevantes para estudiar la labor diplomática republicana, es decir, la expansión hacia el mediterráneo oriental y la confrontación con una tradición helenística. Es en este período donde las fuentes examinadas ofrecen mayores detalles, precisiones y reflexiones en torno a los nuevos desafíos que la institucionalidad y sociedad republicana debieron confrontar, aplicándose y experimentándose transformaciones hoy discernibles en las fuentes.

\section{CORRIENTE REALISTA DE LAS CIENCIAS POLÍTICAS}

Desde la perspectiva de la corriente realista de las ciencias políticas, la búsqueda por el poder se vería supeditada a un complejo sistema interestatal de dominantes y dominados, motivado por un deseo de seguridad en un contexto internacional anárquico y en el cual las disparidades y deseos de poder serían las principales causas de la construcción de los imperios. Ver Waltz; K. (1979, pp. 26-37); Doyle, M. W. (1986, pp. 26-28); Champion, C. (2004, pp. 4-6).

Admitiendo lo anterior, interpretaciones que giran en torno a ciertos actores, personajes o procesos histórico-culturales, deben ser puestas al servicio de la explicación del sistema de relaciones internacionales, donde los actores estatales y su poder de coacción son protagonistas en un panorama interestatal de anarquía, equilibrio de poder o jerarquía hegemónica imperial. Ver Aron, R. (1968); Kaplan, M. (1957). 
En los estudios sobre el mundo antiguo, quizá la primera exposición categórica de este modelo explicativo lo encontramos en el trabajo de Jacqueline de Romilly (1947). Esta autora, analizando en primer lugar la naturaleza imperialista de la Atenas de Pericles narrada por Tucídides, señala que los orígenes de la expansión imperial serían causados por la existencia de motivos y oportunidades brindadas por un sistema internacional anárquico, donde la superioridad del más fuerte sobre el débil actúa como ley inmutable. Solo así es que Atenas y cada imperio antes y después, se desarrolló.

Otros representantes claves de esta lectura de las relaciones internacionales romanas republicanas hacia el oriente, son André Aymard (1938), Paul Pédech (1964, p. 264), Frank Walbank (1965, p. 8 y 1972, p. 173) y, con algunos matices, J-L. Ferrary (1988, pp. 291-306 y 321-348).

Actualmente, el más importante representante de esta escuela realista es el historiador estadounidense A. M. Eckstein (1995, p. 18). Su trabajo viene a representar el discutible éxito académico actual que la lectura de la ciencia política sobre la expansión romana por el Mediterráneo ha obtenido a nivel mundial (Eckstein, 1987, 2006 y 2008). Desde su perspectiva, la diplomacia está al servicio del poder militar y a la amenaza de su uso. Los Estados pequeños deben cooperar prudentemente con Roma para evitar la guerra y el servilismo.

Una última faceta adquiere forma con los trabajos de Ernst Badian (1970) y Rene Pfeilschifter (2005), quienes enfocados sobre todo en las guerras macedónicas y la estrategia llevada a cabo por Tito Quincio Flaminino, aplican una lectura desde la Realpolitik, acusando en el comportamiento romano durante esta campaña, una conducta fundada más que nada en la fuerza y en poco afortunadas aproximaciones diplomáticas, las que de no tener las armas como garantía, caían en el estancamiento o en el fracaso. La política romana y su trabajo diplomático habría sido, sobre todo, una serie de medidas ad hoc, antes que una estrategia de largo aliento determinada por individuos y facciones en el este griego.

\section{DE UNA DIPLOMACIA COERCITIVA A UNA CONCILIATORIA}

Con todo, admitiendo estos puntos de vista bibliográficos de la escuela realista, se abre un tema de investigación para comprender mejor los cambios perceptibles en la diplomacia romana de los siglos III-II a.C.: el tránsito de Roma desde unas relaciones exteriores basadas en la diplomacia coercitiva hacia la conciliatoria. 
Por diplomacia coercitiva se entiende un conjunto coherente de estrategias internacionales, cuyo fin es influenciar las previsiones y conductas de otro Estado mediante la amenaza o el uso parcial de la violencia. Este uso o amenaza de la fuerza no tiene como finalidad destruir al rival, sino atacar su voluntad de lucha y hacerle ver los costos inaceptables de un posible conflicto o continuación del mismo (P. G. Lauren, 1972, p. 135; A. L., George, D. Hall, y D. Simons, 1971).

Es esta diplomacia coercitiva la que se podría homologar a la empleada por Sulpicio Galba ${ }^{1}$, en su trato con las ligas y confederaciones griegas, la que, sin embargo, da lugar paulatinamente a otro tipo de relaciones exteriores, donde el Estado romano decide anteponer el uso de la violencia o la amenaza de su utilización, al arbitraje o arreglos conciliatorios entre Estados aliados (Polibio, 1983, XVI, 27, 1-5). Al respecto, el propio Arthur Eckstein (1988), admitiendo que se trata de un realista político a ultranza, señala que

(...) un examen minucioso de la evidencia sugiere que, si bien Roma rechazó el arbitraje vinculante de sus guerras y disputas (y no actuó a menudo como árbitro ella misma), no rechazó automáticamente la mediación de terceros en sus guerras y disputas, sino que a menudo actuó como mediadora ella misma, y ciertamente no castigó, por tradición, a quienes ofrecieron tal mediación. (p. 414, trad. propia)

Un hito en esta transformación podría ser señalado: la embajada enviada a Antíoco III por el Senado el año 196 a.C. (Polibio, 1983, XVIII, 49-51; Apiano, 1980, Sir, 2-4), donde la experiencia diplomática helenística parece superar a los enviados romanos.

Aún así, la existencia de ambos tipos de diplomacia en una misma época es quizá demostrable hasta cierto punto, pero surgen dos inconvenientes considerables: por un lado, la homologación conceptual presenta serios problemas y, por otro, no es posible visualizar con claridad el predominio

\footnotetext{
${ }^{1}$ Polibio (1981, IX, 42, 6-8; App. Mac. 3) plantea que "[c] uando los romanos conquistaron Egina, los eginetas que no habían logrado escaparse se congregaron en sus naves y rogaron al general vencedor que les permitiera ir a buscar rescate en las ciudades de linaje afín. Primero, Publio les contestó con dureza; les dijo que era antes, cuando todavía eran dueños de sí mismos, cuando debían enviar embajadas a los más potentes en demanda de salvación, y no ahora, que ya eran esclavos. Además prosiguió, ¿no era ridículo que ellos, que hacía poco no se habían ni dignado atender a los legados que les envió, ahora, que habían perdido la libertad, pidieran remitir algunos a ciudades amigas? Con tales palabras echó a los que habían salido a su encuentro. Pero al día siguiente congregó a todos los prisioneros y les dijo que los eginetas no merecían piedad; solo en atención a los griegos restantes les permitía enviar embajadores en busca de rescate, cosa habitual entre los griegos".
} 
de una diplomacia sobre otra, en algún punto posterior. A su vez, en esta mezcla de estrategias de relaciones exteriores coercitivas y conciliatorias, juegan un rol importante otras variantes que pueden escapar a la metodología del realismo político, como son el filohelenismo y los grupos políticos implicados en las tomas de decisiones senatoriales. Son estas variantes disonantes con el realismo político las que otra vía de análisis retoma y hace su eje de trabajo.

\section{EL SENADO ROMANO: FACCIONES, AMICITIA Y DIPLOMACIA UTILITARIA}

Hace mas de cuarenta años que H. H. Scullard y John Briscoe propusieron -el primero de manera tentativa y el segundo de manera concreta- el estudio y comprensión de las luchas internas del Senado entre grupos, líderes y facciones (J. Briscoe, 1969, p. 60; H. H. Scullard, 1951 y 1970. El problema de las alineaciones y convicciones políticas de la aristocracia senatorial era, ya para esa época, un asunto conocido, pero en la línea de un enfoque de estudios en torno al imperialismo (T. Frank, 1914). Sin embargo, es con ellos dos que el estudio de las facciones senatoriales trató de delinear con mayor o menor precisión y éxito una determinada agenda internacional.

John Briscoe (1969, p. 60) buscó delimitar la existencia, a mediados del siglo III-II a.C., de dos facciones senatoriales: por un lado, adquiriendo el nombre de su familia al mando, "los Escipiones", quienes habrían constituido un grupo con mayor o menor coherencia, que aspiraba, apoyados por sus ideas y amistades del este helenístico, a mantener e incentivar el estado de fuerzas en equilibrio que los reinos de los diadocos habían creado. Por otro lado, de un corte tradicionalista, Catón y su círculo habrían formado el grupo de los "Fulvios", que, según Briscoe, instigaba una política internacional impositiva y amenazante.

Habrían sido estas dos facciones las que condujeron de forma alternativa las relaciones exteriores de Roma en el Mediterráneo tras la Segunda Guerra Púnica, existiendo sin embargo, en toda ocasión, senadores y cónsules que sin denotar un bando específico, lograron moverse entre ambas filiaciones. Tal sería el caso de Tito Quincio Flaminino, aunque su política y conducta diplomáticas, señala Briscoe, obedecerían más a la posición de los Escipiones (J. Briscoe, 1972, pp. 22-53; F. Cassola, 1960, pp. 105-130).

No obstante, desde la década del setenta, muchas críticas se han levantado hacia el orden faccional con resonancias internacionales elaborado por 
Briscoe. Muchas veces, en efecto, se logra concluir que pueden existir lazos familiares o matrimoniales entre senadores influyentes, y establecer consecuentemente, potenciales lazos y obligaciones políticas. Sin embargo, no hay suficientes evidencias en la gran mayoría de los casos, como para sostener con fiabilidad, la existencia de grupos senatoriales tan cohesionados, a tal punto de poder construir agendas políticas de largo aliento.

Como ya advertía Robin Seager en 1972:

Ninguna fuente republicana habla de la existencia de más de un factio (en el sentido de grupo político) en algún momento en Roma; incluso en otras comunidades no aparecen más de dos facciones simultáneamente. A ninguna familia en Roma se le atribuye un factio que sea paralelo al factio Barcina en Cartago; no hay rastro de las facciones rivales de la nobleza (Seager, 1972, p. 58, trad. propia).

El uso y las interpretaciones de Briscoe y sus conceptos, parecen puestas en entredicho. Sin embargo, tres puntos quedan por señalar que parecen ofrecer expectativas más positivas:

a) En primer lugar, el propio Seager (1972) agrega a lo anterior que

Por supuesto, esto no significa que ver la historia de la república tardía en términos de luchas entre facciones dentro de la oligarquía senatorial sea necesariamente falso, o que dicha terminología deba ser totalmente evitada. Pero no imaginemos que simplemente escribiendo sobre facciones debemos acercarnos automáticamente a la verdad de aquellos que alguna vez escribieron sobre partidos. (p. 58, trad. propia)

Reconocer que si bien la facción senatorial debe tener sus matices y puede no necesariamente constituir un grupo tan coherente y continuo en el tiempo, como se pensaba en un principio, no significa necesariamente que haya que desestimar los correlatos entre diferentes políticas y medidas diplomáticas llevadas a cabo durante este período. El hecho esencial prevalece: en el Senado cohabitan al menos dos maneras de enfrentarse con los problemas internacionales.

b) En segundo lugar, el admirable trabajo de Marianne Bonnefond-Coudry (1989, pp. 593-711) sobre la constitución, espacios, vocabulario y agrupaciones en el Senado republicano, ofrece a su manera una re-lectura de las filiaciones partidistas en el interior de dicho organismo. Si bien su interpretación en este punto es mucho más moderada en sus conclusiones, recono- 
ce la presencia de grupos político-etarios y la posibilidad de una traducción efectiva de estas diferencias en medidas y estrategias internacionales.

Así, la propuesta que relaciona agrupaciones políticas senatoriales y relaciones exteriores mantiene su vigencia más de una década después de su primer esbozo.

c) En tercer lugar, el trabajo del historiador norteamericano Paul J. Burton (2001), en relación con la amistad internacional romana como un factor capital en la construcción de la diplomacia y el imperialismo romano, ofrece otras pistas útiles. Este discípulo de Arthur Eckstein, abandonando el paradigma realista, opta por el constructivismo, postulando que es mediante las relaciones de amistad entre las aristocracias mediterráneas y romanas que se produce un proceso de mutuo aprendizaje social, creando objetivos y significados compartidos, y suplantando paulatinamente un estado de anarquía y violencia internacional por un sistema conciliatorio y uniforme.

Esta original interpretación de los lazos internacionales desde la óptica personal de las élites sociales del Mediterráneo, implicadas no en una relación jerárquica, como sería el clientelismo, sino en un lazo equitativo basado en la fides, virtus y dones, ofrece un puente teórico y metodológico con los estudios originales de las facciones senatoriales de Briscoe y los sociológicos de Bonnefond-Coudry. Podemos mediante el examen de la amicitia internacional, ampliar el marco interpretativo de los grupos senatoriales y construir uno que explique las oscilaciones de las agendas y grupos políticos al interior del Senado.

De este modo, por ejemplo, si Tito Quincio Flaminino obtiene el 198 a.C., antes de los treinta años, el comando de Macedonia contra Filipo, lo hace ganándose el apoyo del bando filoheleno escipiónico -con el cual ya había tratado en las distribuciones de tierras en Tarento para los veteranos de las campañas hispánicas- $y$ de aquellos Fulvios que aún apoyaban la tradición conservadora de su gens ${ }^{2}$. Una vez en el comando, logra en Grecia y Roma amistades suficientes como para mantener a raya a aquellos contendores al mando, y recibe prórroga tras prórroga, asegurando su triunfo, su prestigio y su nueva clientela griega (Tito Livio, 1993, XXXII, 28, 3; XXXII, $32,5)$. En todo este proceso, no es casualidad ver a las embajadas y conferencias como momentos claves en su campaña y victorias.

\footnotetext{
${ }^{2}$ Briscoe, J. A. (1973, pp. 22-35); Baldson, J. P. V. D. (1967, pp. 177-190). Las tendencias de la historiografía sobre este asunto y la relación de mayor o menor amistad de Flaminino con los Escipiones y otros grupos políticos, como la situación política que rodea los hechos, la analiza con claridad F. Cassola (1960, pp. 105-130).
} 
A diferencia de Publio Vilio y Sulpicio Galba, su estrategia conciliadora y tendiente a generar lazos personales de fides y virtus con los líderes griegos, le permitió generar el suficiente poder mancomunado para atrincherar y forzar a Filipo V a la batalla; allí donde Galba y Vilio optaron por una estrategia de combate a ultranza, Flaminino y la diplomacia hicieron de sus recursos sociales, militares y logísticos, una nueva fórmula de relaciones internacionales que los Escipiones ya habían esbozado en Occidente ${ }^{3}$.

A pesar de ello, aunque esta aproximación metodológica al surgimiento de una nueva diplomacia republicana ofrece interesantes resultados iniciales, abre a su vez dos preocupaciones no menos importantes: por un lado, la amalgama que se logra conjugar entre amistad internacional, facciones senatoriales y la competencia aristocrática por la gloria, no es inmune a la re-lectura del realismo político. Desde el punto de vista neo-realista, esta amalgama explicativa no sería sino un sistema imperialista metrocéntrico, con algunas ligeras variaciones y concesiones al constructivismo, pero al fin y al cabo, puede ser interpretado como Realpolitik, vale decir, la política de la realidad o diplomacia basada en intereses prácticos y acciones concretas, sin atender a la teoría o la filosofía como elementos "formadores de políticas". Por otro lado, este sistema explicativo, que exige arribar a argumentos sólidos desde esta mirada, requiere de una cantidad de ejemplos y evidencias que muchas veces agotan sus significados y resultan de una peligrosa ambigüedad. Con todo, este marco interpretativo es de gran interés, si bien deja aún cabos sueltos que un marco diferente podría ayudar a recopilar y proponer otras soluciones.

\section{LA COMISIÓN SENATORIAL: TRADICIÓN Y REINVENCIÓN MEDITERRÁNEA}

La primera mención de estas comisiones internacionales la encontramos en Polibio, a fines de la primera guerra púnica, cuando el pueblo romano no acepta los acuerdos iniciales obtenidos por las embajadas regulares ${ }^{4}$.

\footnotetext{
3 (Polibio, XVIII, 10, 3; 11,12; Tito Livio, XXXII, 32, 7-8; Plutarco, Flam., 7, 1-2). Los pormenores de toda la actividad diplomática romana hasta concretar la paz están analizados por Filippo Canali de Rossi (2014, pp. 71-78).

${ }^{4}$ Polibio (1970, I, 63, 1): “Cuando el pueblo romano conoció estas condiciones no ratificó los tratados y envió dos legados para que averiguasen lo sucedido. Estos legados no introdujeron en el tratado ningún cambio fundamental y solo agravaron en algo las condiciones impuestas a los cartagineses".
} 
Una segunda referencia a esta figura de la comisión se encuentra en Tito Livio, esta vez a fines de la segunda guerra púnica ${ }^{5}$.

Estas comisiones de diez representantes (decem legati) se nos presentan entonces como un recurso diplomático excepcional, y cuyo fin es tratar en extensión y detalle un problema especialmente delicado y complejo como lo fueron, por ejemplo, los acuerdos de paz con Cartago. En ambos casos, por lo tanto, estas comisiones tienen un trabajo acotado en el tiempo y, además, en el segundo caso, adoptan un rol asesor del cónsul.

Balsdon (1962) considera que decem legati, en latín era una expresión técnica de la comisión enviada por el Senado, por lo general, con ciertas instrucciones generales sobre los grandes temas involucrados, para cooperar con un cónsul o procónsul en la formulación de los detalles de un acuerdo de paz, después de la victoria, o en la redacción y la publicación de la primera (o a veces, la revisión) carta de una provincia (Sobre los decem legati también ver Schleussner,1978; Thomasson, 1991).

Cuando estudiamos la primera comisión senatorial destinada a oriente, el 197-196 a.C., tras la victoria de Flaminino en Cinocéfalos, encontramos nuevos aspectos en estas comisiones. Este organismo mantiene sus roles ya señalados en Polibio y Tito Livio (1993, XXXIII, 30,1; XXXIII, 31,7) para las guerras púnicas, pero ahora observamos nuevos elementos que llaman la atención.

En primer lugar, refiriéndose a su composición, Tito Livio destaca que al momento de su creación, el Senado indicó que la comisión debía incluir a Publio Vilio y Sulpicio Galba, ambos estrechamente relacionados con las operaciones militares y diplomáticas realizadas en Grecia y Macedonia ${ }^{6}$.

Tenemos así un especial interés por parte del Senado de construir una comisión informada plenamente de las realidades y potencialidades del contexto greco-macedónico. La experiencia queda así explícitamente señalada, no solo en cuanto a senadores y su categoría etaria política, sino, además, la experiencia en cuanto al conocimiento personal de un espacio geopolítico especifico ${ }^{7}$.

${ }^{5}$ Tito Livio (1968, XXX, 43, 4): "Las tribus votaron afirmativamente la cuestión sobre la paz, y que fuese Publio Escipión quien la formalizase, y que este trajese de vuelta al ejército. De acuerdo con esta decisión, el senado decretó que Publio Escipión, oído el parecer de diez comisarios, estipulase la paz con el pueblo cartaginés en las condiciones que considerase oportunas".

${ }^{6}$ Tito Livio (1993, XXXIII, 24, 5): [“Se nombró una comisión de diez miembros, de acuerdo con una antigua costumbre, con cuyo asesoramiento expondría Tito Quincio a Filipo las condiciones para la paz; una cláusula adicional del decreto establecía que entre esos diez figurarían Publio Sulpicio y Publio Vilio, que habían estado como cónsules al frente de la provincia de Macedonia”].

${ }^{7}$ G. Clemente (1976, pp. 319-352) demuestra la existencia de especialistas en asuntos diplomáticos en el interior del Senado romano. 
En segundo lugar, los comisionados del 197-196 extienden su abanico de funciones y libertades más allá de las precedentes, como el propio Tito Livio rescata ${ }^{8}$.

Sumado a estos hechos, disponemos de la información sobre una activa participación en las actividades diplomáticas de Flaminino (Tito Livio, 1993, XXXIII, 34, 1), y el reparto de regiones y tareas para implementar los acuerdos de paz con Filipo (Tito Livio, 1993, XXXIII, 35, 1) y su intervención en la conferencia de Lisimaquia con Antíoco9. De este modo, vemos que las tareas de asesorar y detallar o corregir los tratados de paz, ahora están acompañadas de funciones más variadas, continuadas en el tiempo y de mayores libertades y atribuciones. También se dejan ver las diferencias de criterio entre la comisión y Quincio. Los diez comisionados eran partidarios de dar Óreo y Eretria al rey Eumenes, hijo de Atalo, y Quincio no estaba de acuerdo, por lo que se sometió el asunto a la decisión del Senado, entidad que concedió la libertad a esas ciudades (Tito Livio, 1993, XXXIII, 34, 10-11). Llama la atención la participación directa de los comisionados, quienes, en equipo, se distribuyeron tareas como ir personalmente a formalizar la liberación de las ciudades de la región que le correspondió a cada uno. Publio Léntulo, a Bargilias, Lucio Estertinio, Hefestia y Taso y las ciudades de Tracia, Publio Vilio y Lucio Terencio, a encontrarse y reunirse con Antíoco, y Gneo Cornelio, a reunirse con Filipo. Todos estaban ocupados en una tarea de gran responsabilidad, sin lugar a dudas, pero lo más extraordinario es lo que hace Gneo Cornelio; no sabemos si por encargo del Senado o por su propia iniciativa, le pregunta al rey Filipo si estaba dispuesto a prestar oídos a un consejo no solamente útil sino de importancia vital. El rey contestó que incluso le daría las gracias si le hacía alguna sugerencia provechosa para él, ante lo cual lo impulsa, ahora que se había logrado la paz, a dar un paso más allá aún, y enviar nuevamente embajadores a Roma para vincularse formalmente a través de un tratado de alianza y amistad. Este acto lo habría protegido de las sospechas ante la inminencia de la ofensiva que se esperaba de Antioco III (Tito Livio, 1993, XXXIII, 35, 2, 3, 4, 5, 6, 7, 8; Canali de Rossi, 2014, p. 85).

${ }^{8}$ Tito Livio (1993, XXXIII, 31, 1): “...en lo referente a estas tres ciudades (Corinto, Calcis y Demetríade), los diputados tenían instrucciones de hacer decidir, en bien del Estado y de acuerdo con su conciencia, lo que requerirán las circunstancias del interés común".

${ }^{9}$ Tito Livio (1993, XXXIII, 39, 1): “entonces puso gran empeño en convencerlo para que, puesto que había conseguido la paz, enviase embajadores a Roma a pedir un tratado de alianza y amistad, a fin de evitar que pudiera parecer que se había mantenido a la expectativa y aprovechando la ocasión propicia para reiniciar la guerra, en el caso que Antíoco realizase algún movimiento hostil. Este respondió que enviaría los embajadores inmediatamente". 
Aquí vemos que los decem legati, a estas alturas, han superado largamente las responsabilidades que tuvieron en el pasado los legati propiamente tales, que como sabemos, se desempeñaron con una serie de restricciones que limitaban su participación, al punto de que eran solo portadores de mensajes. En este caso, los miembros de estas comisiones tienen facultades no solo para negociar, sino que pueden mantener relaciones directas con los gobernantes e incluso influir en sus decisiones. Si esto fuera visto con los ojos actuales, aparecería como una clara intervención de representantes de la política en el servicio exterior; en el caso que estamos analizando no lo podemos ver de esta manera, porque no está aún configurado este servicio al modo moderno, pero igualmente, nos permite sospechar que estos comisionados conformaron una especie de funcionarios paralelos, proveniente de la política, con más poder y mucha influencia en Roma, y particularmente en el Senado, y cuyas capacidades se distinguían especialmente por sus habilidades como negociadores. Esto queda en evidencia cuando Cornelio se dirige a las Termópilas para asistir a la Asamblea que los griegos llamaban Pilaica, en la cual advierte sobre todo a los etolios que mantuvieran la amistad con el pueblo romano constante y lealmente ${ }^{10}$.

En tercer lugar, la comisión senatorial del 197-196 cumple una nueva e importante función: entregar un estado de cuentas y hechos orientales al Senado. Se puede apreciar ya desde el final de la segunda guerra púnica que la carga diplomática en el Senado, con el recibimiento de embajadas, discursos y debates, se vuelve cada vez más compleja e inmanejable. Esto lleva a la necesidad de obtener mayores y mejores informaciones respecto a los problemas, actores y procesos que existen en el este, para lo cual el Senado parece confiar cada vez más en los relatos de sus embajadores y, con más importancia aún, de sus comisiones (Polibio, 1983, XXII, y XXIV, 1). En el caso concreto del 197/196, es el relato de la comisión, al regresar al Senado, lo que pone en guardia a éste de la amenaza de Antíoco y, más importante aún, de la consonancia de este peligro con el descontento etolio y el poder del tirano Nabis (Tito Livio, 1993, XXXIII, 44, 5). Otro ejemplo es cuando los legados enviados por el rey Éumenes se presentan en Roma para expo-

${ }_{10}$ Tito Livio (1993, XXXIII, 35, 9-10-11-12). Algunos de los etolios "se quejaron sin acritud de que la actitud hacia su pueblo por parte de los romanos no era la misma después de la victoria que durante la guerra; otros fueron más duros en sus acusaciones y recriminaciones, diciendo que sin los etolios no hubieran podido los romanos no ya vencer a Filipo, sino ni siquiera pasar a Grecia". Cornelio, demostrando sus grandes dotes como político y negociador evita responder a estas acusaciones, "para que aquello no desembocase en un altercado, diciéndoles que conseguirían todo lo que fuera justo si presentaban en Roma sus demandas. Y así, de acuerdo con su sugerencia, se acordó el envío de una embajada. Este fue el final de la guerra con Filipo". 
ner, ¿ cómo Filipo se había adueñado de varias ciudades tracias, sumándose a estos enviados de otras regiones en las cuales Filipo se había adueñado de otras ciudades? Ante esto Filipo envió embajadores para defenderse frente a las acusaciones. El Senado en esos días debe haber estado repleto de delegaciones que pronunciaban discursos contra los legados de Filipo, frente a lo cual, el Senado romano, afirma Polibio, "decidió nombrar en el acto una comisión para que examinara las acusaciones contra Filipo y garantizara la seguridad de los que quisieran exponer francamente su opinión y acusar al rey". Para ello nombraron a Quinto Cecilio, Marco Bebio y a Tiberio Claudio (Polibio, 1983, XXII, 6, 2-6).

El 182 a.C. ocurre otro caso del mismo tipo al cual Polibio se refiere:

Acudieron a Roma legados de parte de Éumenes, de Farnaces, de Filipo y también de parte del pueblo aqueo, además de los exiliados de Lacedemonia y de los que ahora retenían la ciudad; el Senado romano les concedió a todos audiencia. A estos y a los legados enviados por Éumenes y por Farnaces, el Senado les contestó que remitiría algunos enviados a inspeccionar los de Sínope, y la disputa surgida entre los dos reyes. Pero habiendo llegado Quinto Marcio procedente de Macedonia, y habiendo informado acerca de Macedonia y del Peloponeso, el Senado ya no necesitaba de muchas palabras. Con todo recibió a los embajadores peloponesios y macedonios, y los escuchó, pero fijó su posición y formuló sus respuestas no según las palabras de los embajadores, sino de acuerdo con el informe de Quinto Marcio, quien había reseñado acerca del rey Filipo, que si bien había cumplido las órdenes, las había acatado de mala gana; si encontraba ocasión, lo iba a hacer todo contra los romanos. Así que el Senado romano respondió a los emisarios de Filipo de un modo tal que felicitaba a este rey por lo que había hecho; con vistas al futuro, creía que debía poner cuidado en no dar la impresión de que hacía algo contra los romanos. En cuanto al Peloponeso, Quinto Marcio había informado: los aqueos no solo se niegan a traspasar cualquier asunto al senado romano, sino que, muy pagados de sí mismos, se proponen resolverlo todo por sí. Con solo que el senado les prestara alguna atención y les diera una leve muestra de disconformidad, Lacedemonia se reconciliaría al punto con Mesenia (...) acontecida esto, proseguía Quinto Marcio, los aqueos acudirían muy satisfechos a refugiarse junto a los romanos. El Senado pues, respondió a Séripo dejando intencionalmente a la ciudad en el aire (...) que esto no les corresponde a ellos. Esta fue la respuesta que dieron: parecía una proclama dirigida a los que, pensando en los romanos precisamente, proyectaban abandonar aquella liga. Por lo demás el senado retuvo a los embajadores, esperando a ver cómo les iba a los aqueos en sus operaciones en Mesenia. (Polibio, 1983, XXIII, 9) 
Este fragmento examinado resulta importante por la relevancia que adquiere el informe diplomático de Quinto Marcio por sobre los alegatos de los embajadores extranjeros. Se trata de un caso único en la obra de Polibio, por cuanto nunca se había observado la conjunción de una embajada romana, su informe al Senado y las consecuencias directas que éste ejercía sobre el rol decisivo senatorial en las relaciones exteriores. Lamentablemente, no existen registros detallados de la actividad de Quinto Marcio en Grecia, pero a partir de su cercanía familiar con la monarquía macedónica, es de esperar que el Senado considerase sus observaciones de mayor valor para los intereses romanos que aquéllas de los representantes griegos. A la vez, destaca en un mismo sentido que, ante la ausencia de palabras del embajador romano sobre el conflicto entre Éumenes y Farnaces, este último emprendiendo con el ataque a Sínope una política militar expansiva, el Senado recién decide adoptar un papel neutro. Todo el suceso nos permite conjeturar que el Senado ha desarrollado a estas alturas un sistema lo suficientemente profesional en su selección, ejecución y registro diplomático que permite al cuerpo republicano fiarse de sus embajadores por sobre los delegados extranjeros, con puntos de vista y argumentos probablemente sesgados.

Por lo tanto, atendiendo a estos cambios en las funciones de las comisiones diplomáticas y su consonancia con la expansión romana en el este a comienzos del siglo II a.C., se abre una interesante posibilidad de estudio, la que podría ofrecer un marco interpretativo de estos cambios como un hito en la transformación de la diplomacia romana republicana: legados geopolíticamente experimentados en la o las tareas asignadas, tiempo de trabajo extenso, funciones más amplias y atribuciones que van cediendo más terreno a la libre determinación del enviado según circunstancias concretas.

Esta lectura diplomática de las comisiones internacionales republicanas no es de por sí un marco teórico ni metodológico. El rol de las comisiones senatoriales es más bien un argumento de interesantes y potenciales conclusiones originales, pero sujetas a la lectura teórica que otras aproximaciones al problema apliquen: ¿son las comisiones un reflejo de más de una conducta coercitiva senatorial conducente a la jerarquía mediterránea?, ¿se trata de un conjunto de ejemplos de cómo los contactos y amistades internacionales fueron ampliando la base de participantes senatoriales? El debate al respecto continúa abierto. Considero que el camino más indicado reside en una simbiosis entre los hallazgos relativos a las comisiones senatoriales y los fundamentos teóricos de la amistad y facciones internacionales del Senado romano. De este modo sería posible comenzar a comprender aquel proceso de intercambio y aprendizaje diplomático entre Roma y el oriente 
helenístico, del cual surgirá un concepto de las relaciones internacionales fundacional para el Imperio romano y germinal para el mundo moderno.

\section{REFLEXIONES FINALES}

Hemos analizado las principales líneas e hipótesis en torno a la diplomacia romana republicana y sus transformaciones durante los siglos III y II a.C. En primer lugar, es necesario señalar una preocupación frente a las aproximaciones de la ciencia política al problema de la diplomacia republicana. Con demasiada regularidad, en estos trabajos, las premisas históricas corren el riesgo de arrastrar tras de sí a los acontecimientos históricos, en vez de mantener un diálogo constante de interpelación entre ambos polos, como considero necesario. Los esfuerzos de Arthur Eckstein por demostrar la existencia de un sistema anárquico de corte helenístico parecen a veces ignorar la existencia en las fuentes de referencias explícitas a los naturales derechos de conquista, las imágenes compartidas de la libertad griega, el funcionamiento regular de las confederaciones, y las discusiones internas en Roma sobre el rol a cumplir como potencia mediterránea (R. BuonoCore, 2002-2003, pp. 46-54).

En segundo lugar, en oposición a esta simplificación de la ciencia política existe la atractiva, pero al mismo tiempo compleja aproximación desde el Senado y sus dinámicas de amistades y facciones internacionales. Si bien opone al primer caso una lectura mucho más fidedigna de las fuentes y sus relatos contradictorios, corre el constante riesgo de convertirse en un relato contradictorio ella misma. La realidad actual es que las fuentes ofrecen fundamentos en general muy débiles para ciertos principios y exigencias metodológicas de esta aproximación.

En tercer lugar, el rol de las comisiones senatoriales, como hito en la transformación de la diplomacia republicana, es quizás el logro más interesante en sí mismo. Sólo así se podrán obtener conclusiones valiosas que permitan leer los hallazgos encuadrados entre las guerras macedónicas y la derrota de Antíoco III como señales de una transformación real en las relaciones internacionales romanas.

Tanto por su paulatina aparición, como por su heterogénea composición y la amplitud de sus atribuciones, estas comisiones de orígenes tan antiguos en la tradición romana adquirieron nuevas responsabilidades que buscaban subsanar las dificultades del Senado de comprender a cabalidad los conflictos que demandaban su atención. Éste es quizás el dato que gene- 
ra mayor atención, pues es un ámbito de investigación que puede producir perspectivas originales respecto a la diplomacia republicana y su transformación a finales del siglo I a.C.

Es posible observar en las fuentes un proceso de maduración y complejización de la labor diplomática romana en directa correlación con los nuevos desafíos que la expansión mediterránea conlleva. Desde las guerras púnicas es posible ver cómo es que Roma va transitando desde una diplomacia de emergencia y coercitiva, hacia un trabajo internacional continuado en el tiempo, preventivo y especializado con las intervenciones en el Mediterráneo oriental. Individuos, familias y facciones van adquiriendo nuevos y diversos rasgos, aptitudes diplomáticas en directa consonancia con las nuevas clientelas y amistades internacionales, introduciendo así nuevos conceptos, intereses y potenciales. Se trata de un proceso que tiene sus hitos más evidentes en los Escipiones, Tito Quincio Flaminino, Servio Sulpicio Galba, Quinto Marcio Filipo y muchos otros. Sin embargo, este proceso no puede ser entendido a cabalidad si no recogemos también a las confederaciones, reinos y monarcas helenísticos, quienes mediante un paulatino contacto internacional entregaron lecciones y conceptos a Roma y sus familias dirigentes: los derechos de conquista y propiedad legítimos, protocolos, argumentos, retórica diplomática, etc. En este sentido queda en evidencia que se requiere examinar estrechamente a Roma y a aquellos con quienes Roma se encontró en su expansión.

Finalmente, el rol del Senado en la construcción de la labor diplomática republicana es un punto que también produce nudos de trabajo interesantes. Más que un estudio jurídico-constitucionalista del rol senatorial, permite estudiar la relación entre las facciones senatoriales, familias y tareas diplomáticas, ofrece la posibilidad de analizar otro factor de profesionalización de embajadas y embajadores. Clientelas, amistades, comercio y gloria militar se entrelazan estrechamente en un sistema competitivo aristocrático de extensión mediterránea, en el cual la diplomacia parece ser una herramienta cada vez más atractiva para perpetuar, extender o destruir ventajas $\mathrm{y}$ atribuciones de grupos o individuos.

\section{REFERENCIAS}

Aron, R. (1968). Peace and War. New York, United States: Praeger Publishers. Aulliard, C. (2006). La diplomatie romaine. L’autre instrument de la conquête. De la foundation à la fin des guerres samnites (753-290 av. J.-C.). Rennes, France: Presses Universitaires de Rennes. 
Aymard, A. (1938). Les premiers rapports de Rome et de la conféderation achaienne. Bordeaux, France: Féret \& fils, éditeurs.

Apiano (1980). Historia Romana, I. (Introducción, traducción y notas de Antonio Sancho Royo). Madrid, España: Editorial Gredos S. A.

Badian, E. (1970). Titus Quinctus Flamininus: Philhelenism and Realpolitik. Cincinnati, United States: University of Cincinnati.

Baldson, J. P.V. D. (1967). Titus Quinctius Flamininus. Phoenix 3(21), 177-190.

Balsdon, J. P.V. D. (1962). Roman History, 65-50 B.C.: Five problems. JRS 52, 137.

Bonnefond-Coudry, M. (1989). Le sénat de la république romaine. De la guerre d'Hannibal à Auguste. Rome, Italie: École Française de Rome.

Botten-Wobst, Th. (1876). De Legationibus. Leipzig, Lipsiae, Deutschland: Typis I.B. Hirschfeldi.

Briscoe, J. (1969). Eastern Policy and Senatorial Politics 168-146 B.C. Zeitschrift für Alte Geschichte, Bd.18, 49-70.

Briscoe, J., (1972). Flamininus and Roman Politics (200-189 B.C.). Latomus 31, 1, 22-53.

Briscoe, J. A. (1973). A commentary on Livy, Books xxxi-xxxiii. Oxford, United Kingdom: Routledge.

Buono-Core, R. (2002-2003). El sentido de la libertad en Atenas y Esparta. Limes 14-15, 46-54.

Burton, P. J. (2001). Friendship and Empire. Roman diplomacy and imperialism in the Middle-republic (353-146 B.C.). Cambridge, United Kingdom: Cambridge University Press.

Canali de Rossi, F. (1997). Le ambascerie dal mondo Greco a Roma in età repubblicana. Roma, Italia: Istituto Italiano per la Storia Antica.

Canali de Rossi, F. (2005). Le relazioni diplomatiche di Roma, vol. I, Dalletà regia alla conquista del primato in Italia (753-265 a.C.). Roma, Italia: Herder Editrice.

Canali de Rossi, F. (2007). Le relazioni diplomatiche di Roma, vol. II, Dall'intervento in Sicilia fino alla invasione annibalica (264-2016 a.C). Roma, Italia: Herder Editrice.

Canali de Rossi, F. (2013). Le relazioni diplomatiche di Roma, vol. III, Dalla resistenza di Fabio fino alla vittoria di Scipione (215-201 a.C.). Roma, Italia: Scienze e Lettere S.r.l.

Canali de Rossi, F. (2014). Le relazioni diplomatiche di Roma, vol. IV, Dalla liberazione della Grecia alla pace infida con Antioco III (201-194 a.C.). Roma, Italia: Scienze e Lettere S.r.l.

Canali de Rossi, F. (2016). Le relazioni diplomatiche di Roma, vol. V, (I), Dalla pace infida alla espulsione di Antioco dalla Grecia (194-190 a.C.). Roma, Italia: Scienze e Lettere S.r.l. Canali de Rossi, F. (2017a). Le relazioni diplomatiche di Roma, vol. VI, (II), Dalla spedizione degli Scipioni in Asia alla pace di Apamea (190-188 a.C.). Roma, Italia: Scienze e Lettere S.r.l.

Canali de Rossi, F. (2017b). Le relazioni diplomatiche di Roma, vol. VII, (III), 
Problemi e contraccolpi della grande espansione egemonica (188-183 a.C.). Roma, Italia: Scienze e Lettere S.r.l.

Canali de Rossi, F. (2018). Le relazioni diplomatiche di Roma, vol. VIII, (IV), La crisi dinastica macedone e le contese interne della Grecia (182-179 a.C.). Roma, Italia: Scienze e Lettere S.r.l.

Cassola, F. (1960). La politica di Flaminino e gli Scipioni. Labeo VI, 105-130.

Catalano, P. (1972-1975). Linee del sistema sovranazionale romano, I. Turín, Italia: Giappichelli Editore.

Champion, C. (2004). Roman Imperialism. Oxford, United Kingdom: Oxford and Malden, MA: Wiley-Blackwell.

Clemente, G. (1976). 'Esperti' ambasciatori del Senato e la formazione della politica estera romana tra il III e il II secolo a.C. Athenaeum III-IV, 319-352.

De Martino, F. (1972-1975). Storia della costituzione romana, 6 vols. Napoli, Italia: Casa Editrice Dott. Eugenio Jovene.

De Romilly, J. (1947). Thucydide et l'imperialisme athénien. Paris, France: Société d'édition Les Belles Lettres.

Doyle, M.W. (1986). Empires. New York, United States: The Edwin Mellen Press.

Eckstein, A. (1987). Senate and General individual decision making and roman foreign relations 264-164 B.C. Berkeley-Los Ángeles-London, United States: University of California Press.

Eckstein, A. (1988). Rome, the War with Perseus, and Third Party Mediation. Zeitschrift für Alte Geschichte, Bd. 37, H. 4, 414-444.

Eckstein, A. (1995). Moral Vision in the Histories of Polybius. Berkeley-Los Angeles, London, United States: University of California Press.

Eckstein, A. (2006). Mediterranean Anarchy, Interstate War and the rise of Rome. Berkeley-Los Angeles, Berkeley-Los Angeles, London, United States: University of California Press.

Eckstein, A. (2008). Rome enters the Greek East. Fron Anarquy to hierarchy in the Hellenistic Mediterranean, 230-170 B.C. Oxford, United Kingdom: Wiley-Blackwell.

Eilers, C. (Ed.) (2009). Diplomats and Diplomacy in the Roman World. LeidenBoston, Germany-United States: Brill.

Ferrary, J-L. (1988). Philhellénisme et impérialisme. Rome, Italie: École française de Rome.

Frank, T. (1914). Roman Imperialism. New York, United States: Macmillan.

Frezza, P. (1938). Le forme federative e la struttura dei rapport internazionali nell'antico diritto romano, Studis et Documenta Historiae et Iuris 4, 363428.

Frézouls, Ed.-Jacquemin, A. (éd.). (1995). Les Relations Internationales, Actes du Colloque de Strasbourg, 15-17 juin 1993, Paris, France: De Boccard.

George, A. L., Hall, D. \& Simons, D. (1971). The limits of Coercive Diplomacy. Boston, United States: Little, Brown and Company.

Kaplan, M. (1957). System and Process. New York, United States: R. E. Krieger Publishing Company. 
Knibbe, P. (1958). Die römischen Gesandtshaften nach den Osten in der Zeit von 230-129 v. Chr. Viena, Austria: editado por Wolfgang Haase.

Krug, E. (1916). Die Senatsboten der römischen Republi. Breslau, Deutschland: Breslau Editor.

Lauren, P. G. (1972). Ultimata and Coercive Diplomacy. International Studies Quaterly 2(16), 131-165.

Pédech, P. (1964). La méthode historique de Polybe, Paris, France: Les Belles Lettres.

Pfeilschifter, R. (2005). Titus Quinctius Flamininus. Untersuchungen zur römischen Griechenlandpolitik. Göttingen, Deutschland: Vandenhoeck \& Ruprecht.

Phillipson, C. (1911). The international Law and Custom of Ancient Greece and Rome, 2 vols. London, United Kingdom: MacMillan.

Plutarco (2007). Vidas paralelas, IV (Introducción, traducción y notas de Juan M. Guzmán Hermida y Óscar Martínez García). Madrid, España: Editorial Gredos S. A.

Polibio (1970). Las Historias de Polibio de Magalópolis, Libros I-VI (Traducción, introducción y notas de Genaro Godoy A.). Santiago, Chile: Ediciones de la Universidad de Chile-Editorial Andrés Bello.

Polibio (1981). Historias, Libros V-XV (Traducción y notas de Manuel Balasch Recort). Madrid, España. Editorial Gredos S. A.

Polibio (1983). Historias, Libros XVI-XXXIX (Traducción y notas de Manuel Balasch Recort). Madrid, España: Editorial Gredos S. A.

Roldán, J. M. (2016). La República Romana. Madrid, España: Cátedra.

Schleussner, B. E. (1978). Die legaten der römischen Republik: decem legati und sändige Hilfsgesandte. München, Deutschland: Beck.

Scullard, H. H. (1951). Roman Politics, 220-150 B.C. Oxford, United Kingdom: Oxford at the Clarendon Press.

Scullard, H. H. (1970). Scipio Africanus: soldier and politician. Bristol, United Kingdom: Thames and Hudson.

Seager, R. (1972). Factio: some observations. JRS 62, 58.

Torregaray, E. (2005). Embajadas y embajadores entre Hispania y Roma en la obra de Tito Livio, Diplomacia y autorrepresentación en la Roma Antigua (pp. 25-61). Vitoria-Gasteiz, España: Servicio Editorial, Universidad del País Vasco.

Torregaray, E. (2014). Embajadas en Hispania: los confines simbólicos del Imperio en occidente, Confins et périphéries dans l'occident romaine (pp. 463474). Limoges, France: Presses universitaires de Limoges.

Thomasson, B. E. (1991). Legatus. Beiträge zur römische verwaltungeschichte. Stockholm, Sverige: Timpe Editor.

Thurm, A. (1883). De Romanorum legatis republicae temporibus ad externas nationes nissis, diss. Leipzig, Deutschland: Th. Botten-Wobst.

Tito Livio (1968). Storia di Roma, Libri XXVIII-XXX (Testo Latino e versione di Guido Vitali). Bologna, Italia: Zanichelli Editore. 
Tito Livio (1993). Historia de Roma desde su fundación, Libros XXXI-XXXV (Traducción y notas de José Antonio Villar Vidal). Madrid, España: Editorial Gredos S. A.

Veyne, P. (1975). Y a-t-il un imperialisme romain. MEFR 87, 753-855.

Walbank, F.W. (1965). Political Morality and the friend of Scipio. JRS 55, 1-16.

Walbank, F.W. (1972). Polybius. Berkeley and Los Angeles, United States, University of California Press.

Waltz, K. (1979). Theory of international Politics. Massachussets, United States: Addison-Wesley Publishing Company.

Willems, P. (1878-1885). Le Sénat de la République romaine, 2 vols. Lovaina, Belgique: Edcn. de Lovaina, Ch. Peeters. 